Int. J. Electrochem. Sci., 13 (2018) $7907-7922$

\title{
Improved Mechanical Properties and Corrosion Resistance of Nickel-Aluminum Bronze (NAB) Alloys by Controlling the Grain Size of Ni Coatings
}

\author{
Chao Feng, Yi Xie, Jun Wang, Yi Long, Wei Chen, Dengke Li, Wenbo Li, Kejian Ouyang \\ State Grid Hunan Electric Power Company Limited Research Institute, Changsha 410007, China; \\ *E-mail: 676459812@qq.com
}

doi: 10. 20964/2018.08.40

Received: 17March2018/ Accepted: 13 June 2018 / Published: 5 July 2018

\begin{abstract}
The surface of nickel-aluminum bronze (NAB) alloy was modified by electrodepositing Ni coating for the purpose of improving the surface mechanical and corrosion properties of the alloy. The effects of grain size (from $18 \mathrm{~nm}$ to $2 \mathrm{um}$ ) on corrosion behaviors of $\mathrm{Ni}$ coatings produced by controlling the electrodepositionin parameters without any grain refiner were characterized by the electrochemical workstation and the neutral salt spray (NSS) test. Transmission electron microscope (TEM) and X-ray diffraction (XRD) were used to confirm the microstructure and grain size of Ni coating. The Vickers microhardness of Ni coatings ranged between $186.70 \mathrm{HV}$ to $235.325 \mathrm{HV}$, higher than that of NAB alloy $(182.467 \mathrm{HV})$. The electrochemical results show that Ni coatings on NAB alloy improve corrosion resistance of the substrate alloy (NAB) and Ni coatings exhibit increasing corrosion resistance withdecrease in grain size. Results of the salt spray test (The monitoring of corrosion behavior over extended periods of up to 110 days)support that Ni coatings improve the corrosion resistance of NAB substrate and thegrain sizeof $\mathrm{Ni}$ coatings has a significant impact on its corrosion resistance, observed by the scanning electron microscope (SEM) coupled with energy dispersive X-ray (EDX) analyser. The experimental results can bereasonablyexplained byhigher density grain boundaries of smaller grain size provide more nucleation sites for passive films.
\end{abstract}

Keywords:Electrodeposition, Nickel-aluminum bronze(NAB) alloys, Ni coating, Grain size, Corrosion resistance

\section{$\underline{\text { FULL TEXT }}$}

(C) 2018 The Authors. Published by ESG (www.electrochemsci.org). This article is an open access article distributed under the terms and conditions of the Creative Commons Attribution license (http://creativecommons.org/licenses/by/4.0/). 